\title{
Effect of Acoustic Material Ceiling to Speech Performance of CONVENTION HALL
}

\section{Pengaruh Material Akustik Pada Langit-Langit terhadap KinerJa WICARA PADA CONVENTION HALL}

\author{
M.S. Prawirasasra ${ }^{1}$, M.R.T. Cahaya ${ }^{2}$, Suwandi ${ }^{3}$ \\ Program Studi S1 Teknik Fisika, Fakultas Teknik Elekro, Universitas Telkom ${ }^{1}$ \\ bibinprawirasasra@ telkomuniversity.ac.id \\ Program Studi S1 Teknik Fisika, Fakultas Teknik Elekro, Universitas Telkom² \\ Program Studi S1 Teknik Fisika, Fakultas Teknik Elekro, Universitas Telkom ${ }^{3}$
}

\begin{abstract}
During design process of auditorium, mostly, acoustics design was neglected by engineers therefore it may cause inappropriate acoustic condition. Evaluation of acoustic comfort was carried out through measurement of speech parameters such as Noise rating (NR), reverberation time and definition $\left(D_{50}\right)$. According to measurement result, performance of convention hall is not sufficient to perform speech activities since it has 0.4-13.7 s of reverberation time and 1.6-42.6\% of D50. To improve acoustic performance, modification is applied on ceiling materials using combination of two different acoustic materials - absorber and diffusor, through simulation.. The result has shown that installment of full absorber at ceiling with high absorbtive coefficient could reduce early energy reflection which causes lower reverberation time and higher definition. Whenever ceiling are made of combination of two type of materials, the position of di on ceiling depend on diffusor orientation. Spread diffusor has better performance rather than centralized diffusor. However, the acoustic performance of convention hall remains the same.
\end{abstract}

Keywords: speech, improve, modification, ceiling, simulation

\section{PENDAHULUAN}

Gedung convention hall merupakan sebuah ruangan tertutup yang umum digunakan untuk sejumlah aktivitas. Pada dasarnya, setiap bangunan tertutup harus mampu mengakomodasi seluruh kebutuhan okupan selama berada di dalam gedung sehingga aktifitas dapat berjalan sesuai dengan tujuannya. Umumnya ada beberapa hal yang menjadi perhatian dalam proses perancangan gedung yaitu kenyamanan termal, ventilasi, pencahayaan, estetika dan hal lainnya. Namun, para desainer gedung sering kali mengabaikan kenyamanan akustik sebagai salah satu pertimbangannya (Salter, 2003). Faktor Kondisi aktual akustik dapat dievaluasi dengan melakukan pengukuran sesuai dengan prosedur yang tercantum pada ISO 3382-1:2009, Acoustic, measurements of room acoustic parameters - Part 1: Performance spaces. Parameter akustik yang dievaluasi disesuaikan berdasarkan tujuan pembangunan ruang tersebut secara akustik.

Objek penelitian ini adalah sebuah fasilitas pendidikan yang dimiliki oleh Universitas Telkom, Indonesia. Pada dasarnya, bangunan ini memiliki geometri yang unik yaitu memiliki bentuk setengah silinder dengan floor plan yang berbentuk fan/kipas. Berdasarkan penelitian sebelumnya, bangunan dengan geometri dengan bentuk langit-langit cekung dapat menyebabkan fenomena pemfokusan suara 
(Iannace, 2016). Adanya efek tersebut dapat menyebabkan cacat akustik yang berupa rendahnya derajat keseragaman tingkat tekanan suara, tingginya derajat perbedaan parameter di antara area penerima serta coloration (Iannace, 2016). Geometri langit-langit berupa dome juga dapat menurunkan waktu dengung (Prodi, 2003). Selain geometri, parameter monoaural akustik sangat dipengaruhi oleh volume ruang tertutup dan jenis material penyusun ruangan tersebut (Iannace, 2017),(Cirillo, 2003).

Kebutuhan untuk melakukan perancangan ulang gedung sering kali tidak dapat dihindari. Namun hasil perancangan tidak mungkin untuk diterapkan dengan metode trial and error karena akan memakan biaya yang sangat tinggi. Solusinya adalah dengan melakukan simulasi desain akustik sebelum tahap konstruksi ataupun implementasi. Terdapat banyak penelitian yang telah berhasil melakukan pemodelan kondisi akustik sebuah bangunan (Baron, 2012), (Mahdavi, 2008). Simulasi kondisi akustik juga merupakan hal yang harus dipertimbangkan untuk dilakukan dalam proses desain sebuah bangunan ataupun gedung (Schmidt, 2005). Oleh karena itu, tahap awal dari proposal peningkatan kinerja akustik juga dilakukan melalui simulasi ( $\mathrm{Su}, 2005)$, (Bo, 2016).

Pada penelitian ini, kondisi aktual dari objek akan dievaluasi melalui pengukuran. Hasil pengukuran akan dibandingkan dengan nilai rekomendasi untuk aktivitas wicara. Ketidaksesuaian antara nilai pengukuran dengan rekomendasi menyatakan bahwa objek memiliki kinerja akustik yang tidak sesuai dengan aktivitasnya. Peningkatan kinerja dilakukan dengan melakukan modifikasi terhadap material langit-langit yang dilakukan melalui simulasi.

\section{OBJEK PENELITIAN}

Telkom University Convention Hall (TUCH) merupakan salah satu gedung yang berada di lingkungan kampus Telkom University. Gedung ini memiliki rancangan yang unik dan menarik dan memiliki daya tampung yang sangat besar yaitu sekitar 2507 orang. Kedua hal tersebut menjadi daya tarik sehingga sering digunakan sebagai tempat penyelenggaran untuk kegiatan yang bersifat massal. Secara akustik, seluruh kegiatan yang diselenggarakan dapat dikategorikan sebagai aktivitas wicara ataupun bermusik.

Bangunan ini terdiri atas tiga lantai yaitu basement, lantai dasar dan lantai ke-2. Setiap lantai memiliki fungsinya masing-masing namun hanya lantai dasar saja yang digunakan sebagai area utama untuk tempat pertunjukkan. Basement dan lantai 2 hanya berfungsi sebagai unit pendukung kegiatan saja. Sedangkan pada lantai dasar terdapat dua zona yaitu koridor dan main hall termasuk stage dan backstage. Fungsi koridor adalah sebagai tempat sirkulasi ataupun akses bagi pengunjung yang akan masuk ke area main hall. Sedangkan main hall merupakan tempat berlangsungnya pertunjukan. Bangunan ini memiliki memiliki bentuk lantai dasar yang menyerupai kipas yang dibatasi oleh langitlangit berbentuk semi silinder atau cekung. Ilustrasi pembagian zona serta bentuk geometri di lantai dasar dapat dilihat pada Gambar 1.

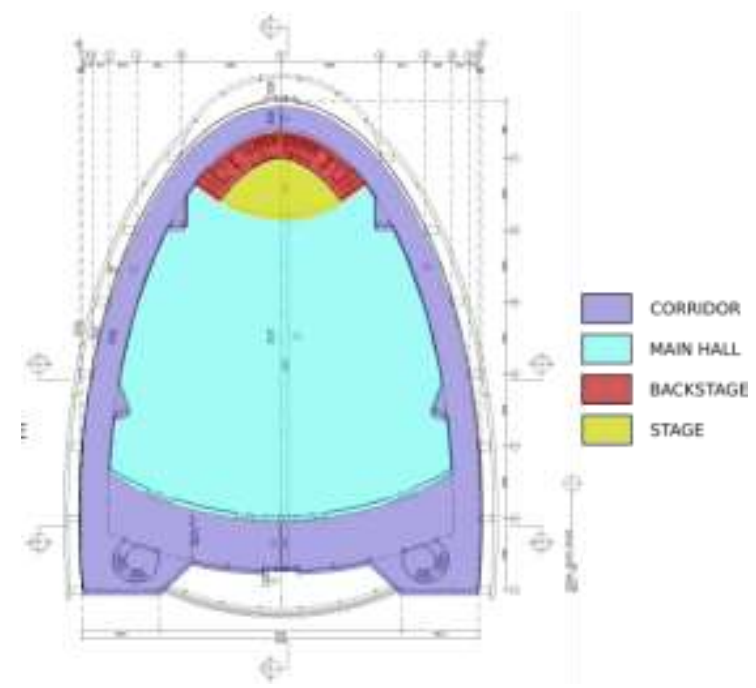

Gambar 1. Floor plan dan zonasi pada lantai dasar TUCH

Diantara kedua zona tersebut, yaitu koridor dan main hall, tidak ada bidang batas yang membatasi kedua area secara utuh. Pembatas yang memisahkan hanya berupa dinding vertikal dengan ketinggiannya yang jauh lebih kecil dibandingkan dengan jarak antara dinding-langit-langit. Akibatnya terdapat area kosong yang sangat luas dan menghubungkan seluruh zona yang terdapat pada main hall. Ilustrasi dari pembatas fisik dari TUCH dapat 
dilihat pada proyeksi tampak depan dan samping pada Gambar 2.

Dalam kondisi standar, TUCH hanya berupa ruang kosong yang tidak dilengkapi panggung, kursi, furnitur, public address (PA) ataupun perlakuan akustik. Material gedung penyusun interior adalah painted-concrete block, paintedunglazed brick dan glass untuk dinding. Sedangkan lantai terbuat dari marble dan polyurethane foam digunakan untuk melapisi bagian dalam langit-langit. Berdasarkan nilai koefisien absorbsi yang cukup kecil maka seluruh material penyusun interior dapat digolongkan sebagai reflektor atau material dengan fungsi utama untuk memantulkan suara. Informasi mengenai besarnya koefisien absorbsi dapat dilihat pada Tabel 1 .

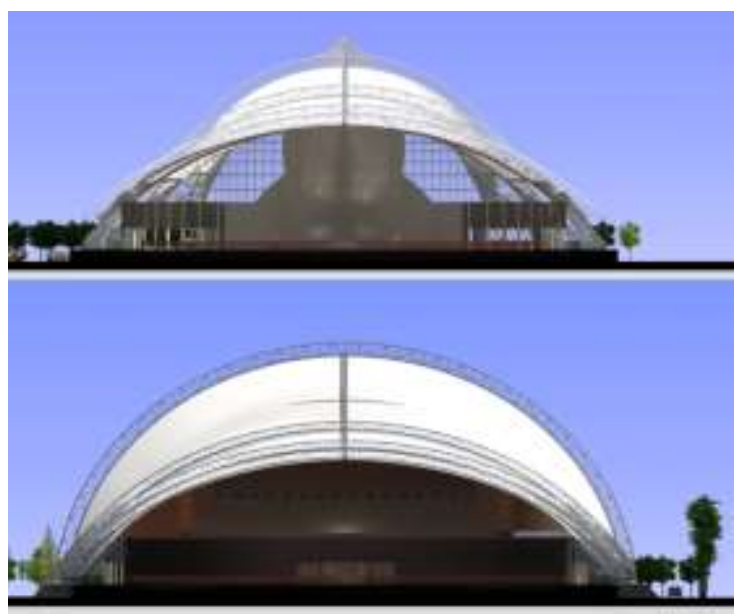

Gambar 2. Proyeksi tampak samping dan depan gedung TUCH

Tabel 1. Koefisien absorbsi, dalam \% (Egan, 2007).

\begin{tabular}{lcccccc}
\hline & \multicolumn{7}{c}{ Frekuensi (Hz) } \\
\hline & 125 & 250 & 500 & $1 \mathrm{k}$ & $2 \mathrm{k}$ & $4 \mathrm{k}$ \\
\hline Concrete & 10 & 5 & 6 & 7 & 9 & 8 \\
Glass (large panes) & 18 & 6 & 4 & 3 & 2 & 2 \\
Brick (painted) & 1 & 1 & 2 & 2 & 2 & 3 \\
Marble & 1 & 1 & 1 & 1 & 2 & 2 \\
Polyurethane foam & 7 & 11 & 20 & 32 & 60 & 85 \\
\hline
\end{tabular}

\section{DASAR TEORI}

Convention Hall dengan fungsi percakapan dirancang agar pendengar dapat memahami secara utuh dan jelas mengenai informasi yang disampaikan oleh/dari sumber suara. Selama propagasi dari sumber ke penerima, gelombang suara akan berinteraksi dengan medium maupun dengan material interior penyusun bidang batas ruangan. Interaksi ini dapat berupa difraksi, difusi, absorbsi ataupun refleksi akibat tumbukan dengan permukaan material. Akibatnya gelombang yang diterima oleh pendengar akan mengalami distorsi atau mempengaruhi kualitas suara yang diterima (Yilmaz, 2005).

Suara yang diterima merupakan kombinasi antara suara langsung dan suara pantulan atau tidak langsung. Gelombang pantul memegang peranan penting dalam kinerja akustik dan sangat dipengaruhi oleh bentuk langit-langit. Beberapa cacat akustik yang disebabkan oleh geometri langit-langit adalah echo, pantulan akhir serta pemusatan suara. Ilustrasi dari cacat akustik dapat dilihat pada Gambar 3.

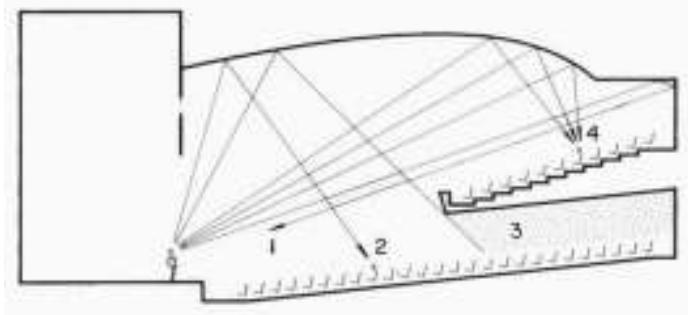

Gambar 3. Cacat akustik akibat geometri langitlangit. (1) Echo, (2) Pantulan akhir, (3) Shadow zone dan (4) Pemusatan suara (Yilmaz, 2005).

Properti fisis dari gelombang pantul yang dikuantifikasi menjadi parameter akustik wicara berupa energi \& jumlah pantulan serta waktu tiba. Parameter akustik yang berkaitan dengan energi dan jumlah pantulan adalah waktu dengung atau reverberation time $\left(\mathrm{T}_{60}\right)$. Parameter ini menggambarkan kemampuan suatu ruangan untuk meluruhkan energi suara sebesar $60 \mathrm{~dB}$. Semakin tinggi energi pantul maka ruangan dianggap akan semakin hidup ataupun dengung. Dengan kombinasi energi pantul yang tinggi dan jumlah pantulan yang banyak maka dapat menyebabkan terjadinya echo. Persamaan matematis untuk mencari waktu dengung (sabine) adalah sebagai berikut:

$R T=\frac{0,161 \mathrm{~V}}{A}$.

dengan RT adalah waktu dengung (s), V adalah volume $\left(\mathrm{m}^{3}\right)$ dan $\mathrm{A}$ adalah penyerapan rata-rata sabins.

Namun, pantulan tidak seluruhnya merugikan terutama pantulan yang tergolong sebagai 
pantulan dini yaitu pantulan yang diterima pada rentang $50 \mathrm{~ms}$ pertama setelah sumber suara dibunyikan. Jumlah energi yang diterima pada rentang tersebut diharapkan sangat besar karena akan membantu kejelasan wicara. Terkait dengan hal tersebut, parameter akustik yang digunakan sebagai evaluator adalah Deutchklit $\left(D_{50}\right)$. Parameter $D_{50}$ didefinisikan sebagai perbandingan antara jumlah energi pada $50 \mathrm{~ms}$ pertama dengan energi total yang diterima. Secara matematis dapat dinyatakan sebagai berikut

$$
D_{50}=\frac{\int_{0}^{50} p^{2}(t) d t}{\int_{0}^{\infty} p^{2}(t) d t}(\%)
$$

dengan $\mathrm{p}$ adalah amplitude tekanan $(\mathrm{Pa})$. Untuk energi pantulan yang diterima setelah $80 \mathrm{~ms}$ pertama, maka dapat energi tersebut dapat menyebabkan ketidaknyamanan secara akustik karena dapat menyebabkan echo.

Terdapat nilai optimum yang disarankan agar aktivitas wicara di dalam gedung dapat berlangsung dengan baik. Jika hasil pengukuran menunjukan angka yang tidak berada dalam rentang yang diinginkan maka objek perlu dilakukan redesain secara akustik.

Tabel 2. Nilai RT terhadap persepsi wicara

\begin{tabular}{l|l}
\hline RT $(\mathrm{s})$ & Persepsi wicara \\
\hline$<0,5$ & Sangat teredam, tidak terdengar \\
$0,5-1.0$ & Sangat baik \\
$1,0-1,5$ & Baik \\
$1,5-2,0$ & $\begin{array}{l}\text { Cukup } \\
\text { Buruk, suku kata tidak terdengar dengan } \\
\text { baik }\end{array}$ \\
\hline
\end{tabular}

\section{METODE PENELITIAN}

Langkah awal dari penelitian ini adalah melakukan pengukuran langsung di lapangan. Hasil pengukuran akan digunakan sebagai data aktual mengenai kondisi akustik objek serta digunakan sebagai acuan nilai benar ketika melakukan simulasi. Hasil pengukuran juga akan digunakan sebagai evaluator terhadap kondisi akustik wicara, apakah perlu dilakukan redesain atau tidak.

Tabel 3. Rentang D50 terhadap persepsi wicara (Marshall, 1994)

\begin{tabular}{l|l}
\hline Definisi & $\mathrm{D}_{50}(\%)$ \\
\hline Excellent & $86-100$ \\
Very good & $67-86$ \\
Good & $39-67$ \\
Bad & $17-39$ \\
Terrible & $6-16$ \\
\hline
\end{tabular}

Pengukuran maupun definisi parameter akustik yang dilakukan mengikuti prosedur yang disyaratkan oleh ISO 3382-1:2009, Acoustic, measurements of room acoustic parameters Part 1: Performance spaces. Lokasi pengambilan data disesuaikan dengan kondisi aktual penggunaan TUCH yaitu stage sebagai posisi pembicara digunakan sebagai posisi speaker dan microphone sebagai penerima berada di posisi area audiens. Speaker yang digunakan memiliki indeks arah omnidirectional yang didekati melalui dodecahedron speaker. Selama pengukuran, posisi speaker berada tepat di garis tengah dari floor plan dan diletakan di area stage. Ketinggian speaker dari lantai adalah 1,5 m.

Sedangkan, area penerima diwakikan oleh sebanyak 99 titik yang tersebar merata di seluruh main hall dengan koridor tidak termasuk area analisis. Konfigurasi titik pengukuran adalah memiliki jarak minimal antar tiap titik pengukuran dalam 1 baris adalah 1,5 m serta jarak minimum untuk titik dengan jarak terdekat dengan dinding adalah $1 \mathrm{~m}$. Pada penelitian ini, jarak yang digunakan adalah sekitar $4 \mathrm{~m}$ antara titik pengukuran. Microphone diletakkan sejauh 1,2 m dari lantai agar sesuai dengan ketinggian posisi telinga manusia ketika duduk.

Langkah berikutnya adalah melakukan simulasi. Input dari simulasi adalah jenis sumber suara, koefisien absorbsi, posisi penerima serta geometri bangunan. Hasil yang 
diperoleh dari simulasi akan di validasi dengan data yang diperoleh dari pengukuran. Nilai errornya tidak boleh melebihi nilai Just Noticeable Different (JND) untuk setiap parameter uji. Pada penelitian ini, error RT yang diijinkan adalah maksimal bernilai 5\% (Bo, 2016).

Selanjutnya, simulasi akan dilakukan dengan kondisi langit-langit yang telah dimodifikasi. Material akustik yang digunakan adalah berupa absorber dan diffusor. Simulasi akan dilakukan dengan beberapa konfigurasi pemasangan langit-langit yaitu: (1) seluruhnya absorber, (2) seluruhnya diffusor serta (3) kombinasi diffusor dan absorber.

Untuk konfigurasi (1), simulasi dilakukan dengan mengganti absorber dengan koefisien absorbsi yang bervariasi. Material absorber yang digunakan adalah (A1) sheep wool absorbent $100 \mathrm{~mm}$, (A2) Fiberglass 2,5 cm, (A3) acoustic plaster $40 \mathrm{~mm}$, (A4) $5 \mathrm{~cm}$ wood wool dan (A5) heavy carpet with latex. Nilai koefisien absorbsi dari ke-5 material dapat dilihat pada Tabel 4.

Tabel 4. Koefisien absorbsi material, dalam (\%) (Cox, 2009)

\begin{tabular}{c|c|c|c|c|c}
\hline Frek (Hz) & A1 & A2 & A3 & A4 & A5 \\
\hline 125 & 47 & 15 & 30 & 8 & 8 \\
250 & 86 & 55 & 35 & 17 & 27 \\
500 & 99 & 80 & 50 & 35 & 70 \\
$1 \mathrm{k}$ & 94 & 90 & 70 & 45 & 35 \\
$2 \mathrm{k}$ & 96 & 85 & 70 & 65 & 11 \\
$4 \mathrm{k}$ & 99 & 80 & 70 & 65 & 4
\end{tabular}

Pada konfigurasi (2), diffusor yang digunakan dalam simulasi adalah (B1) Semi Eclips Diffusor $20 \mathrm{~cm}$, (B2) Schroeder Diffuser $20 \mathrm{~cm}$, (B3) Curved surface $20 \mathrm{~cm}$, (B4) Curved surface $30 \mathrm{~cm}$ dan (B5) Semicylinder diffuser $30 \mathrm{~cm}$. Koefisien diffuse dari kelima sample yang digunakan dapat dilihat pada tabel 5 .

Selanjutnya, dalam konfigurasi (3), material langit-langit akan dimodifikasi materialnya berupa kombinasi antara absorbser dan diffusor dengan lokasi dan orientasi pemasangan tertentu.

Tabel 5. Koefisien Diffusi, dalam (\%) (Cox, 2009).

\begin{tabular}{c|c|c|c|c|c}
\hline Frek. (Hz) & B1 & B2 & B3 & B4 & B5 \\
\hline 125 & 16 & 2 & 4 & 51 & 23 \\
250 & 25 & 2 & 5 & 20 & 26 \\
500 & 87 & 21 & 18 & 16 & 91 \\
$1 \mathrm{k}$ & 62 & 19 & 39 & 59 & 86 \\
$2 \mathrm{k}$ & 87 & 39 & 56 & 58 & 88 \\
$4 \mathrm{k}$ & 94 & 49 & 56 & 55 & 94 \\
\hline
\end{tabular}

Absorber \& diffusor yang digunakan pada konfigurasi ke-3 hanya yang menghasilkan kinerja akustik terbaik berdasarkan simulasi pada konfigurasi (1) dan (2) saja. Untuk konfigurasi (3), berikut adalah kombinasi pemasangan material: (a) absorber dipasang dibagian kanan \& kiri dengan diffusor dibagian tengah langit-langit, (b) diffusor dipasang di bagian kiri \& kanan sedangkan sisanya adalah absorber dan (c) diffusor dipasang secara terpusat dibagian belakang langit-langit. Ilustrasi dari kombinasi untuk konfigurasi terakhir dapat dilihat pada Gambar 4.

\section{ANALISIS DAN DISKUSI}

Hasil pengukuran kinerja akustik untuk parameter waktu dengung dapat dilihat pada Tabel 5. Data yang digunakan adalah nilai waktu dengung pada frekuensi $1000 \mathrm{~Hz}$ karena telinga manusia sangat sensitif. Berdasarkan tabel tersebut, terlihat bahwa waktu dengung memiliki rentang yang cukup lebar yaitu berkisar antara 0,46-13,74 detik. Analisis statistik standar deviasi terhada sebaran pengukuran parameter waktu dengung menghasilkan nilai sebesar 3,49 s dengan nilai rata-rata sebesar $5,17 \mathrm{~s}$ menyatakan bahwa titik pengukuran di dominasi oleh nilai waktu dengung yang berada pada rentang kategori 'Buruk'. Kondisi ini bukan merupakan kondisi akustik yang semestinya. Seharusnya semua titik pengukuran berada pada rentang yang berada dalam kategori 'sangat baik'.

Hasil pengukuran $\mathrm{D}_{50}$ dapat dilihat pada Tabel 6 . Nilai $D_{50}$ juga menggambarkan kualitas yang sama dengan waktu dengung. Dengan nilai diantara 0,1-42,65 \%, menyatakan bahwa tingkat kejelasan percakapan di dalam TUCH berada dalam kategori 'Good'-'Terrible'. 


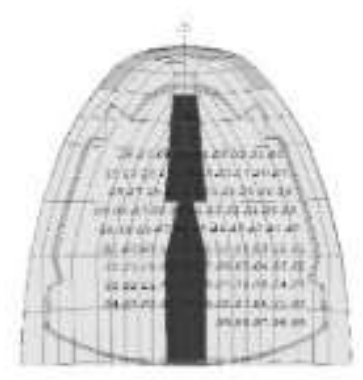

(a)

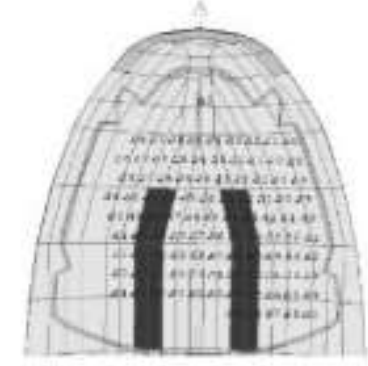

(b)

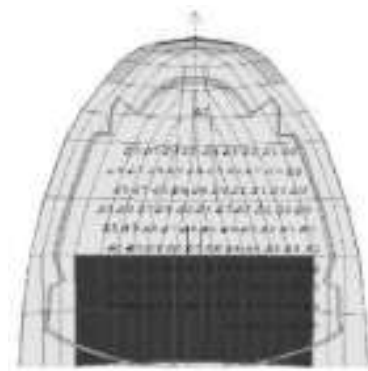

(c)

Gambar 4. Konfigurasi pemasangan (3) dengan kombinasi (a), (b) dan (c). Warna gelap adalah material diffusor sedangkan warna terang adalah absorber.

Tabel 4. Hasil pengukuran RT pada $1000 \mathrm{~Hz}$

\begin{tabular}{l|c}
\hline Parameter & Hasil pengukuran \\
\hline Maksimum (s) & 13,74 \\
Minimum (s) & 0,46 \\
Rata-rata (s) & 5,17 \\
Standar deviasi (s) & 3,49 \\
\hline
\end{tabular}

Tabel 5. Hasil pengukuran $\mathrm{D}_{50}$ pada $1000 \mathrm{~Hz}$

\begin{tabular}{l|c}
\hline Parameter & Hasil pengukuran \\
\hline Maksimum (\%) & 42,65 \\
Minimum (\%) & 0,1 \\
Rata-rata (\%) & 9,89 \\
Standar deviasi (\%) & 9,51 \\
\hline
\end{tabular}

Informasi dari kedua parameter tersebut menyatakan bahwa gedung TUCH tidak memiliki kinerja yang cukup baik untuk digunakan sebagai tempat aktivitas wicara. Ada beberapa hal yang menjadi penyebab tingginya nilai serta tidak meratanya kedua nilai parameter tersebut. Karakter permukaan penyusun interior yang bersifat reflektif mengakibatkan setiap pantulan yang terjadi memiliki energi yang tinggi sehingga jumlah pantulan menjadi sangat banyak. Faktor lainnya adalah panjang lintasan rambat medium atau volume ruangan yang sangat besar hampir tidak berpengaruh pada peluruhan energi selama proses propagasi karena penyerapan energi oleh medium rambat adalah sangat kecil. Dimensi ruangan yang besar juga berkontribusi pada jarak propagasi gelombang. Berdasarkan nilai D50 yang cenderung kecil, karakter pantulan pada TUCH adalah memiliki energi total sangat besar namun amplitude energi datang pada waktu yang diinginkan, $50 \mathrm{~ms}$ pertama, amplitudanya sangat kecil. Artinya gelombang pantul membutuhkan waktu yang cukup lama untuk sampai pada penerima. Ini berkaitan dengan ukuran dimensi dari TUCH yang sangat besar.

Langkah berikutnya yang dilakukan adalah melakukan pemodelan geometri dari objek. Input yang dibutuhkan pada simulasi adalah geometri dan dimensi, koefisien absorbsi \& difusi serta karakter sumber suara dan titik penerima. Sebagai tahap awal, model awal akan akan dikalibrasi terhadap hasil pengukuran. Error maksimal yang diijinkan adalah sebesar 5\% untuk parameter RT/ waktu dengung. Jika hasil simulasi belum memenuhi persyaratan, maka koefisien absorbsi akan disesuaikan agar RT pemodelan memiliki nilai yang berada dalam rentang toleransi. Modifikasi properti material akustik dilakukan karena model geometri sudah disesuaikan dengan kapasitas piranti lunak.

Hasil simulasi peningkatan melalui penambahan material absorber di langit-langit dengan beberapa kombinasi dapat dilihat pada tabel 7 dengan $\mathrm{D}_{50}$ dan RT dinyatakan dalam satuan $\%$ dan detik. Penambahan material absorber dengan koefisien penyerapan yang bervariasi ternyata belum dapat mengubah kategori RT menjadi 'baik' ataupun 'sangat baik'. Ternyata penambahan material absorber belum mampu mengeleminasi pengaruh volume medium rambat yang besar dan energi pantul yang besar terhadap nilai RT.

Namun, penambahan absorber secara umum mampu meningkatkan kualitas $D_{50}$ yaitu menjadi kategori 'good' sampai 'very good'. Peningkatan terbaik terjadi jika menggunakan material A1, yaitu material dengan kemampuan 
absorbsi tertinggi. Dampaknya adalah energi pantul yang diterima menjadi berkurang yang berdampak pada meningkatnya rasio antara energi pantulan awal dengan energi total.

Tabel 7. Nilai rata-rata parameter hasil simulasi dengan konfigurasi (1)

\begin{tabular}{|c|c|c|c|c|c|c|}
\hline \multirow{2}{*}{$\begin{array}{c}\text { Frek. } \\
(\mathrm{Hz})\end{array}$} & \multicolumn{2}{|c|}{ A1 } & \multicolumn{2}{c|}{ A2 } & \multicolumn{2}{c|}{ A3 } \\
\cline { 2 - 7 } & D50 & RT & D50 & RT & D50 & RT \\
\hline 125 & 58,6 & 2,35 & 45,4 & 3,16 & 52 & 2,56 \\
\hline 250 & 70 & 2,40 & 59,5 & 2,25 & 50,4 & 2,72 \\
\hline 500 & 71,8 & 2,62 & 67,7 & 2,47 & 57,6 & 2,37 \\
\hline $1 \mathrm{k}$ & 70,4 & 2,62 & 69,7 & 2,63 & 63,7 & 2,43 \\
\hline $2 \mathrm{k}$ & 70,8 & 2,61 & 68,5 & 2,55 & 64,1 & 2,42 \\
\hline $4 \mathrm{k}$ & 75,2 & 2,03 & 71,3 & 1,92 & 68,7 & 1,88 \\
\hline
\end{tabular}

Tabel 7. Nilai rata-rata parameter hasil simulasi dengan konfigurasi (1) - lanjutan

\begin{tabular}{|c|c|c|c|c|}
\hline \multirow{2}{*}{$\begin{array}{c}\text { Frek. } \\
(\mathrm{Hz})\end{array}$} & \multicolumn{2}{|c|}{ A4 } & \multicolumn{2}{c|}{ A5 } \\
\cline { 2 - 5 } & $\mathrm{D}_{50}$ & RT & D50 & RT \\
\hline 125 & 41,7 & 3,65 & 41,9 & 3,65 \\
\hline 250 & 39,9 & 4,09 & 46,2 & 3,16 \\
\hline 500 & 50,9 & 2,69 & 64,7 & 2,42 \\
\hline $1 \mathrm{k}$ & 54 & 2,49 & 49,1 & 2,80 \\
\hline $2 \mathrm{k}$ & 62,4 & 2,39 & 36,9 & 4,55 \\
\hline $4 \mathrm{k}$ & 67,2 & 1,87 & 43 & 3,58 \\
\hline
\end{tabular}

Simulasi dengan konfigurasi (2) memiliki hasil yang sangat kontras dengan konfigurasi (1). Hasilnya dapat dilihat pada tabel 8 dengan $\mathrm{D}_{50}$ dan RT dinyatakan dalam \% dan detik. Efek dari penambahan material diffusor pada langitlangit adalah menambah energi pantul bukan mengurangi. Hal ini terlihat dari kualitas nilai rata-rata RT dan D50 menjadi lebih buruk dibandingkan dengan kondisi aktual.

Berdasarkan data yang diperoleh dari Tabel 7 dan Tabel 8, material dengan hasil terbaik diperoleh dengan menggunakan A1 dan B1 sehingga konfigurasi (3) akan menggunakan kedua material tersebut. Hasil simulasi untuk konfigurasi (3) untuk seluruh kombinasi material ditampilkan pada Tabel 9.
Tabel 8. Nilai rata-rata parameter hasil simulasi dengan konfigurasi (2)

\begin{tabular}{|c|c|c|c|c|c|c|}
\hline \multirow{2}{*}{$\begin{array}{c}\text { Frek. } \\
(\mathrm{Hz})\end{array}$} & \multicolumn{2}{|c|}{ B1 } & \multicolumn{2}{c|}{ B2 } & \multicolumn{2}{c|}{ B3 } \\
\cline { 2 - 7 } & D50 & RT & D50 & RT & D50 & RT \\
\hline 125 & 44,8 & 3,11 & 38,4 & 4,51 & 35,7 & 4,46 \\
\hline 250 & 39,1 & 4,05 & 28,3 & 8,16 & 25,7 & 7,48 \\
\hline 500 & 38,2 & 3,06 & 27,5 & 7,04 & 19,8 & 6,99 \\
\hline $1 \mathrm{k}$ & 47,5 & 2,58 & 25,3 & 7,84 & 19,6 & 7,53 \\
\hline $2 \mathrm{k}$ & 38,2 & 3,13 & 26,3 & 6,53 & 22 & 6,51 \\
\hline $4 \mathrm{k}$ & 46,6 & 2,24 & 36,1 & 3,87 & 31 & 3,88 \\
\hline
\end{tabular}

Tabel 8. Nilai rata-rata parameter hasil simulasi dengan konfigurasi (2) - lanjutan

\begin{tabular}{|c|c|c|c|c|}
\hline \multirow{2}{*}{$\begin{array}{c}\text { Frek. } \\
(\mathrm{Hz})\end{array}$} & \multicolumn{2}{|c|}{ A4 } & \multicolumn{2}{c|}{ A5 } \\
\cline { 2 - 5 } & D 50 & RT & D50 & RT \\
\hline 125 & 31,7 & 4,49 & 38,1 & 4,49 \\
\hline 250 & 26,3 & 7,60 & 27,9 & 8,01 \\
\hline 500 & 28 & 7,11 & 27,8 & 7,07 \\
\hline $1 \mathrm{k}$ & 21,8 & 7,51 & 23,7 & 7,60 \\
\hline $2 \mathrm{k}$ & 24,6 & 6,49 & 24,7 & 6,49 \\
\hline $4 \mathrm{k}$ & 35,5 & 3,88 & 35,2 & 3,88 \\
\hline
\end{tabular}

Tabel 9. Nilai rata-rata parameter hasil simulasi dengan konfigurasi (3)

\begin{tabular}{|c|c|c|c|c|c|c|}
\hline \multirow{2}{*}{$\begin{array}{c}\text { Frek. } \\
(\mathrm{Hz})\end{array}$} & \multicolumn{2}{|c|}{ (a) } & \multicolumn{2}{c|}{ (b) } & \multicolumn{2}{c|}{ (c) } \\
\cline { 2 - 7 } & D50 & RT & D50 & RT & D50 & RT \\
\hline 125 & 55,4 & 2,4 & 57,3 & 2,35 & 54,1 & 2,54 \\
\hline 250 & 62,5 & 2,3 & 67,8 & 2,36 & 62,6 & 2,35 \\
\hline 500 & 65,1 & 2,52 & 68,5 & 2,63 & 62,4 & 2,51 \\
\hline $1 \mathrm{k}$ & 65,5 & 2,56 & 68,5 & 2,63 & 62,4 & 2,51 \\
\hline $2 \mathrm{k}$ & 64,7 & 2,52 & 68,5 & 2,56 & 63,1 & 2,45 \\
\hline $4 \mathrm{k}$ & 62,4 & 2,51 & 63,1 & 2,45 & 69,1 & 1,92 \\
\hline
\end{tabular}

Hasil dari simulasi menunjukkan bahwa langitlangit yang terdiri atas absorber dan diffusor memiliki nilai rata-rata yang relatif konstan untuk parameter $\mathrm{RT}$ maupun $\mathrm{D}_{50}$. Tidak ada perbedaan yang besar antara nilai maksimum dan minimum di seluruh frekuensi.

Hal ini tentunya menjadi kelebihan dari konfigurasi ini. Pemasangan material juga harus menjadi pertimbangan karena ketiga 
kombinasi tersebut memiliki nilai parameter yang berbeda. D50 terbaik ditunjukan oleh kombinasi (b) sedangkan parameter RT terendah dihasilkan oleh kombinasi (c). Meskipun demikian, seluruh konfigurasi ini belum mampu memenuhi persyaratan akustik yang disarankan untuk digunakan sebagai fasilitas wicara.

\section{KESIMPULAN}

Pada penelitian ini telah berhasil dilakukan evaluasi kondisi akustik dari gedung TUCH dengan metode pengukuran. Hasil yang diperoleh menunjukkan bahwa objek studi tidak memiliki desain akustik yang baik untuk digunakan sebagai tempat aktivitas berbicara.

Usaha peningkatan kinerja akustik dilakukan melalui simulasi dengan mengubah material langit-langit. Berdasarkan simulasi dari seluruh konfigurasi pemasangan material langit-langit, belum ada konfigurasi yang sesuai untuk melakukan aktivitas wicara. Perlu diperhatikan bahwa posisi material absorber dan diffusor harus diperhatikan karena akan berdampak terhadap kinerja akustik.

\section{UCAPAN TERIMA KASIH}

Penulis berterima kasih kepada Laboratorium Akustik dan Fisika Bangunan, Program Studi Teknik Fisika, Institut Teknologi Bandung atas bantuannya selama pengerjaan penelitian ini.

\section{REFERENSI}

Bo, E., Kostara-Konstaninou, E., Lepore, F., Shtrepi, L., Puglisi, G.E., Astolfi, A. 2016. Acoustic Characterization of the Ancient Theatre of Tyndaris: Evaluation and Proposals for its Reuse. $23^{\text {rd }}$ International Congress on Sounds \& Vibration, Greece.

Boren, B.B., Longair M. 2012. Acoustic Simulation of the Church of San Fransicso della Vigna. $164^{\text {th }}$ Meeting of The Acoustical Society of America.

Cirillo, E., Martellotta, F. 2003. Acoustics of Apulian-Romanesque Churches:

Correlations Between Architectural and
Acoustic Parameters. Building Acoustic, 10(1):55-76

Cox, T.J. 2009. Acoustic Absorbers and Diffusers: Theory Design and Application. John Wiley \& Sons Inc.

Egan, M.D. 2007. Architectural Acoustics. McGraw-Hill Custom Publishing.

Iannace, G., Trematerra, A. 2017. Study on the Effects of the Harmonic Choir Stalls in The Church of the Certosa di San Martino in Naples. Building Acoustic 24(3), 159-72.

Iannace, G., Di Gabriele, M. Sicurella, F. 2016. Sound Focusing Effects in Horseshoe Plan Theater. Building Acoustics, 10(2):11733.

Mahdavi, A., Kainrath, B., Orehonuig, K., Lechleitner, J. 2008. Measurement and Simulation of Room Acoustics Parameters in Traditional and Modern Bath Buildings. Building Simulation, 1(3), 223-233.

Marshall, L.G. 2014. An Acoustic Measurement Program for Evaluating Auditorium Based on The Early/Late Sound Energy Ratio. Journal of The Acoustical Society of America, 96, 2551-2261.

Prodi, N. Marsilo, M. 2003. On the Effect of Domed Ceiling in Worship Spaces: A Scale Model Study of a Mosque. Building Acoustics, 10(2):117-33.

Salter, C., Powell, K., Begault, D. 2003. Case Studies of a Method for Predicting Speech Privacy in The Contemporary Workplace. Summary Report.

Schmidt, A., M., D., Kirkegaard, P.H. 2005. From Architectural Acoustic to Acoustic Architectural Using Computer Simulation. Building Acoustic, 12(2), 85-98.

$\mathrm{Su}$, Z., Yilmazer, S. 2005. The Acoustical Performance Analysis of Bilkent Amphitheater: Proposal for Acoustical Renovation. Architectural Science Review 49(2): 167-178.

Yilmaz, T. 2005. Acoustical Analysis of a Multipurpose Hall by Computer Simulation Method: Metu Northern Cyprus Campus Auditorium (NCCA) as Case Study. (Doctoral dissertation, Middle East Technical University). 